\title{
Pain Regulation in Nonsuicidal Self-injury
}

\section{Jiang $Y$ and Jianing You*}

Center for Studies of Psychological Application and School of Psychology, South China Normal University, China

Non-suicidal self-injury (NSSI), a new disorder included in the "conditions for further study" section of the fifth edition of the Diagnostic and Statistical Manual of Mental Disorders [1], refers to a deliberate behavior that directly damages one's own body tissue without suicidal intention [2]. This behavior has become a major public health concern among adolescents, affecting about $18 \%$ of community adolescents all over the world [3].

This high prevalence of NSSI may make people wonder why so many adolescents engage in this behavior. We may think that NSSI must cause physical pain. It is against the innate and evolutionary drive of self-preservation. However, although getting involved hurting oneself, as many as $80 \%$ of adolescent self-injurers reported little or no pain while engaging in the act [4]. Laboratorial studies using various NSSI proxies (e.g., cold, heat, electric shock) also provided supports for the diminished pain perception in individuals with NSSI $[5,6]$. Regarding the mechanism underlying the relationship between diminished pain perception and NSSI, studies suggested that emotion dysregulation and self-invalidation may act as potential mediators $[7,8]$.

Apart from the abnormal physical pain perception, the engagement in NSSI also involves social pain dysregulation. Social pain is associated with actual or potential damage to one's sense of social connection or social value and is often described by the language of physical pain (such as broken hearts, or hurt feeling) across a variety of cultures $[9,10]$.

Interpersonal disturbances, particularly in the family context, may influence the development of NSSI in adolescence [11]. It is suggested that the overall quality of attachment with parents in childhood, injury in parent-child bonds, and experiences of separation and loss may contribute to later NSSI [11-13]. Additionally, maternal emotional neglect (e.g., lack of maternal care), paternal insecure attachment, lack of intimacy within the parent-child relationship, and family invalidation were reported to be associated with NSSI [12,14-16]. In short, when there are problems in parent-child relationships, which are the most important social connections, individuals may suffer social pain, which may then lead to the engagement in NSSI.

Non-suicidal self-injury is not the privilege of humans. Other animals may also engage in NSSI. It is thus meaningful to explore this phenomenon in non-human primates, even in other mammals [17]. Approximately $10 \%$ of animals under individual caging (i.e. social isolation) engage in NSSI [18]. Isolated animals, both with and without abnormal rearing, may exhibit NSSI. Besides, the duration of isolation, and the beginning age of isolation may play a key role in determining the extent of risk for later developing NSSI [19].

Previous research suggests that both physical pain and social pain dysregulations may be involved in NSSI. In fact, considerable evidence has been showing that social pain shares parts of the same phenomenological, neurological, and psychological systems with physical pain $[10,20]$. We thus speculate that one important function of NSSI may be social pain regulation, by means of inflicting physical pain on the body. Several studies have provided preliminary evidence for this speculation, such that acute physical pain (NSSI-proxy) was found to lead to emotional benefits $[2,21,22]$. Additionally, only under conditions of interpersonal distress did heightened physical pain tolerance among self-injurers occur [23]. Therefore, although most past studies focused on the emotion regulation function of NSSI [24,25], we suggest future research to consider pain regulation as an important mechanism underlying the engagement in NSSI.

\section{Funding Information}

This research was funded in part by National Natural Science Foundation of China (Grant No. 31300874). The funder had no role in the decision to publish or preparation of the manuscript.

\section{References}

1. American Psychiatric Association (2013) Diagnostic and statistical manual of mental disorders. ( $5^{\text {th }}$ edn), American Psychiatric Publishing, Arlington.

2. Nock MK (2010) Self-injury. Annu Rev Clin Psychol 6: 339-363.

3. Muehlenkamp JJ, Claes L, Havertape L, Plener PL (2012) Internationa prevalence of adolescent non-suicidal self-injury and deliberate self-harm. Child Adolesc Psychiatry Ment Health 6: 10.

4. Nock MK, Joiner TE Jr, Gordon KH, Lloyd-Richardson E, Prinstein MJ (2006) Non-suicidal self-injury among adolescents: diagnostic correlates and relation to suicide attempts. Psychiatry Res 144: 65-72.

5. Hooley JM, Ho DT, Slater J, Lockshin A (2010) Pain perception and nonsuicida self-injury: a laboratory investigation. Personal Disord 1: 170-179.

6. McCoy K, Fremouw W, McNeil DW (2010) Thresholds and tolerance of physical pain among young adults who self-injure. Pain Res Manag 15: 371-377.

7. Franklin JC, Aaron RV, Arthur MS, Shorkey SP, Prinstein MJ (2012) Nonsuicidal self-injury and diminished pain perception: the role of emotion dysregulation. Compr Psychiatry 53: 691-700.

8. Glenn JJ, Michel BD, Franklin JC, Hooley JM, Nock MK (2014) Pain analgesia among adolescent self-injurers. Psychiatry Res 220: 921-926.

9. Panksepp J (1998) Affective neuroscience: The foundations of human and animal emotions. Oxford university press.

10. Macdonald G, Leary MR (2005) Why does social exclusion hurt? The relationship between social and physical pain. Psychol Bull 131: 202-223.

11. Suyemoto KL (1998) The functions of self-mutilation. Clin Psychol Rev 18: 531 554

12. Gratz KL, Conrad SD, Roemer L (2002) Risk factors for deliberate self-harm among college students. Am J Orthopsychiatry 72: 128-140.

13. Walsh BW, Rosen PM (1988) Self-mutilation: Theory, research, and treatment. Guilford Press, New York.

14. Heath NL, Toste JR, Nedecheva T, Charlebois A (2008) An examination of nonsuicidal self-injury among college students. J Ment Health Couns 30: 137156.

15. Yates TM, Tracy AJ, Luthar SS (2008) Nonsuicidal self-injury among "privileged" youths: longitudinal and cross-sectional approaches to developmental process. J Consult Clin Psychol 76: 52-62.

16. You J, Leung $F$ (2012) The role of depressive symptoms, family invalidation and behavioral impulsivity in the occurrence and repetition of non-suicidal self-injury in Chinese adolescents: a 2-year follow-up study. J Adolesc 35: 389-395.

17. Dellinger-Ness LA, Handler L (2006) Self-injurious behavior in human and nonhuman primates. Clin Psychol Rev 26: 503-514.

'Corresponding author: Jianing You, Center for Studies of Psychological Application and School of Psychology, South China Normal University, Guangzhou 510631 China, E-mail: youjianing@gmail.com

Received December 22, 2014; Accepted December 23, 2014; Published December 30, 2014

Citation: Jiang Y, You J (2014) Pain Regulation in Nonsuicidal Self-injury. J Psychol Abnorm Child 4: e102. doi:10.4172/2329-9525.1000e102

Copyright: ( 2014 Jiang Y, et al. This is an open-access article distributed under the terms of the Creative Commons Attribution License, which permits unrestricted use, distribution, and reproduction in any medium, provided the original author and source are credited. 
18. Reinhardt V, Rossell M (2001) Self-biting in caged macaques: Cause, effect, and treatment. J Appl Anim Welfare Sci 4: 285-294.

19. Lutz C, Well A, Novak M (2003) Stereotypic and self-injurious behavior in rhesus macaques: a survey and retrospective analysis of environment and early experience. Am J Primatol 60: 1-15.

20. Eisenberger NI (2012) Broken Hearts and Broken Bones A Neural Perspective on the Similarities Between Social and Physical Pain. Curr Dir Psychol Sci 21: 42-47.

21. Klonsky ED (2007) The functions of deliberate self-injury: a review of the evidence. Clin Psychol Rev 27: 226-239.

22. Bresin K, Gordon KH, Bender TW, Gordon LJ, Joiner Jr TE (2010) No pain, no change: Reductions in prior negative affect following physical pain. Motiv Emotion 34: 280-287.

23. Gratz KL, Hepworth C, Tull MT, Paulson A, Clarke S, et al. (2011) An experimental investigation of emotional willingness and physical pain tolerance in deliberate self-harm: the moderating role of interpersonal distress. Compr Psychiatry 52: 63-74.

24. Klonsky ED (2009) The functions of self-injury in young adults who cut themselves: clarifying the evidence for affect-regulation. Psychiatry Res 166 : 260-268.

25. You J, Lin MP, Leung $F$ (2013) Functions of nonsuicidal self-injury among Chinese community adolescents. J Adolesc 36: 737-745. 